\title{
Cumulative Radiation Exposure from Diagnostic Imaging in Zagazig University Pediatric Intensive Care and Chest Units Tarek Abd El-Rahman Atiyyah ${ }^{1}$, Mohammed Sanad Naguib Nasr ${ }^{1}$, Talaat Salahdin Ahmed ${ }^{2}$, Marwa Mohamed Sabri Abdelmonem Mostafa*1 Departments of ${ }^{1}$ Pediatrics and ${ }^{2}$ Radiation Physics Atomic Energy Commission, Faculty of Medicine - Zagazig University \\ *Corresponding author: Marwa Mohamed Sabri Abdelmonem Mostafa, Mobile: (+20) 01008455951, Email: tgems_18@yahoo.com
}

\begin{abstract}
Background: The medical use of ionizing radiation has expanded worldwide. The use of radiation in pediatric imaging (e.g. radiographs and computed tomography) saves lives and has a great clinical value for the diagnosis of pediatric illness and injury. However, inappropriate or unskilled use of such technologies may result in unnecessary exposure that may increase risk of malignancy occurrence.

Objective: To detect the effect of multi exposure and its application on reaching to risk threshold of radiation through quantification of the cumulative effective dose (CED) of ionizing radiation attributable to diagnostic imaging in Pediatric Intensive Care Unit (PICU) and Chest Unit, Zagazig University Hospitals. Also, to examine the patterns of use of diagnostic $\mathrm{X}$-ray imaging in these units.

Patients and Methods: This study was conducted in Pediatric ICU and Chest Unit at Zagazig University Hospital from October 2018 to March 2019. 72 cases were included. Selected cases were observed and followed up in each time they were asked to perform x-ray radiography or CT film during their whole stay period in the hospital.

Results: The median of x-ray + ct group was 37.9 msv in our study. Also, in our study, there was dose variation among units. The median of exposure of patients of Chest Unit was 6.51. While the median of patients of ICU was 1.9. Dose of CT in our study formed $53.8 \%$. Our study revealed that CT chest equaled about 30 chest X-ray in our hospital. $74 \%$ of patients had very low and low risks.

Conclusion: Cumulative exposure dose (CED) of ionizing radiation due to frequent X-ray films and CT scans in our study aren't likely to cause acute toxicity as they were relatively low but they may cause chronic toxicity and increases the long-term risk for developing malignancy.
\end{abstract}

Keywords: Cumulative Radiation Exposure, Diagnostic Imaging, Pediatric Intensive Care, Chest Units.

\section{INTRODUCTION}

The medical use of ionizing radiation has expanded worldwide. The use of radiation in pediatric imaging (e.g. radiographs and computed tomography) saves lives and has a great clinical value for the diagnosis of pediatric illness and injury. However, inappropriate or unskilled use of such technologies may result in unnecessary exposure that may increase risk of malignancy occurrence ${ }^{(1)}$. High amounts of exposure (e.g. cancer radiation therapy) are known to cause pulmonary toxicity ${ }^{(2)}$.

Although one chest radiograph has a similar amount of ionizing radiation equal that of 3 days of environmental exposure, which is a minimal amount, the cumulative dose of repeated studies can be serious (3). The biological effects of ionizing radiation target the DNA molecule principally.

Two kinds of effects are observed on tissues: 1 Deterministic effects; occur when damage occur to a large number of cells leading to affection of tissue structure or function, which are considered as tissue reactions e.g. erythema, hair loss, nausea, diarrhea, sterility. There is a certain threshold, above which, these effects can occur. 2- Stochastic effects that occur when cells are modified but not killed (e.g. cancer if the transformation occurred in a somatic cell \& hereditary disease if the transformation occurred in a germ cell). There is no definite threshold, above which, these effects can occur, as it depends on organ sensitivity, mitotic cycle and other factors ${ }^{(4)}$.

The study aimed to detect the effect of multi exposure and its application on reaching to risk threshold of radiation through quantification of the cumulative effective dose (CED) of ionizing radiation attributable to diagnostic imaging in PICU and Chest Unit, Zagazig University Hospitals. Also, to examine the patterns of use of diagnostic $\mathrm{X}$-ray imaging in these units.

\section{PATIENTS AND METHODS}

\section{I- Technical Design}

a) Setting: this study was conducted in Pediatric ICU and Chest Unit, Zagazig University Hospital from October 2018 to Mars 2019.

b) Population or subjects: admitted patients in ICU and Chest Unit, whose age ranged from 1 month to 15 years at Zagazig University Hospital.

c) Type of study: cohort study. 
d) Sample size: 72 cases were included in the study as a comprehensive sample in the study period of 6 months.

e) Inclusion criteria: admitted cases with frequent radiation exposure (at least one X-ray or $\mathrm{CT}$ ).

f) Exclusion criteria: cases that did not expose to radiological imaging for diagnosis, refusal of consent.

\section{Operational design:}

1. Data of selected cases like name, age, weight, duration of stay, mechanically ventilated or not, duration of mechanical ventilation and clinical diagnosis of cases were collected and recorded.

2. Selected cases were observed and followed up in each time they were asked to perform $\mathrm{x}$-ray radiography or CT film during their whole stay period in the hospital and in each time, the radiation dose entered their bodies throughout the imaging process was measured and recorded. At the end of stay, cumulative ionizing radiation dose of each case from all its imaging procedures was calculated.

3. 15 millisivert is the determined level to differentiate between low (if the dose is below 15 $\mathrm{mSv}$ ) and high exposure (if the dose is above 15 $\mathrm{mSv})^{(5)}$.

\section{Measurement of x-ray radiography doses:}

$\mathrm{X}$-ray imaging of cases was performed in the radiology unit of the hospital. A pen dosimeter (200 mR, ARROW-TECH, American, Model 138) was used to measure radiation doses from $\mathrm{x}$-ray imaging procedures by putting beside the patient during each imaging process and then the absorbed dose was read across a scale inside it and recorded then discharged by the pen discharger to be used for the next time.

\section{Measurement of $\mathrm{CT}$ radiation doses:}

CT films of cases were performed in the Radiology Unit of the hospital. A film badge (American-speed, size $30.5 * 40.5 \mathrm{~mm}$ ) was used to measure radiation doses from $\mathrm{CT}$ imaging procedures by putting multiple film badges on the patient around the organ required to be imaged and then these film badges readings had been taken at Atomic Energy Commission after calibration process and the mean of readings was recorded for each imaging time. Pediatric patients are classified according to risks for developing malignancy from medical diagnostic imaging into: very low, low, moderate and high-risk patients.

This classification depended on:

- Type and number of the medical diagnostic studies.

- Sex of the exposed patient.

- Age at time of studies.

- Total radiation doses.

The risk calculation was done through American Society of Radiologic Technologists (ASRT) website (www.XrayRisk.com).
After entering those data about exposed patients and interpretation of the results using risk qualification table of Biological Effects of Ionizing Radiation report (6).

\section{Ethical Approval:}

Informed consent was obtained from parents of each child participating in this study after informing them about the details after approval of Ethical Committee and Institutional Review Board (IRB), Faculty of Medicine, Zagazig University.

\section{Statistical Analysis}

All data were collected, tabulated and statistically analyzed using SPSS version 19. Continuous Quantitative variables were expressed as the mean \pm SD \& median (range). Categorical qualitative variables were expressed as absolute frequencies (number) \& relative frequencies (percentage).

Continuous data were checked for normality by using Shapiro Walk test. Mann-Whitney test (MW) was used to compare two groups of not normally distributed data. Kruskall-wallis test (KW) was used to compare more than two groups of not normally distributed data. Categorical data were compared using Chi-square test. Pearson's correlation (coefficient correlation=r) was used to detect degree of correlation between two quantitative variables.

All tests were two sided. P-value $\leq 0.05$ was considered statistically significant (S), P-value $<0.001$ was considered highly statistically significant (HS), and p-value > 0.05 was considered statistically insignificant (NS).

\section{RESULTS}

Table (1) showed that the age of the studied cases ranged from 1.5 month to 15 years with median of 1.9 years. Weight of the studied group ranged from 2.25 to $54 \mathrm{Kg}$ with median of $10 \mathrm{Kg}$. Regarding sex distribution $54.2 \%$ were male.

Table (1): Demographic data of the studied cases

\begin{tabular}{|c|c|c|}
\hline Variable & \multicolumn{2}{|c|}{$(n=72)$} \\
\hline Age: (year) & \\
\hline Median & \multicolumn{2}{|c|}{1.96} \\
\hline Range & \multicolumn{2}{|c|}{1.5 month -15} \\
\hline Weight: (Kg) & \\
\hline Median & \multicolumn{2}{|l|}{10} \\
\hline Range & \multicolumn{2}{|c|}{$2.25-54$} \\
\hline Variable & $\mathbf{N}$ & $\%$ \\
\hline Sex: & & \\
\hline Male & 39 & 54.2 \\
\hline Female & 33 & 45.8 \\
\hline
\end{tabular}

Table (2) showed that the median number of radiological images among the studied group was 7 with median 7 for $\mathrm{x}$-ray and 1 for CT. 
Table (2): Radiological images among the studied cases

\begin{tabular}{|l|c|}
\hline Variable & (n of cases $=\mathbf{7 2}$ ) \\
\hline Radiological studies in & $(\mathrm{n}=72)$ \\
patient: & 7 \\
Median & $1-36$ \\
Range & $(\mathrm{n}=71)$ \\
\hline X ray studies: & 7 \\
Median & $1-36$ \\
Range & $(\mathrm{n}=29)$ \\
\hline CT studies: & 1 \\
Median & $1-2$ \\
Range & \\
\hline
\end{tabular}

Table (3) showed that the total images done were 610 study with $95.2 \%$ x-ray and $4.8 \% \mathrm{CT}$. Most frequent image in both $\mathrm{x}$-ray and $\mathrm{CT}$ was chest ( $97.1 \%$ \& $71.9 \%$ respectively).
Regarding $\mathrm{x}$-ray doses in the studied patients, this table showed that the highest exposure to $\mathrm{x}$-ray doses was found among patients who underwent abdominal $x$-ray with median of 0.63 $\mathrm{mSv}$ in each single film done to the patients, followed by patients underwent spinal cord x-ray and chest \& neck x-ray $(0.40$ and $0.30 \mathrm{mSv}$ respectively). The one patient who underwent body bone $\mathrm{x}$-ray was the least one to be exposed to $\mathrm{x}$-ray doses $(0.16 \mathrm{mSv})$. The highest exposure to CT doses was found among a patient who underwent cerebral angio CT with median of $7.50 \mathrm{mSv}$ in a single CT film, followed by patients underwent chest and brain CT (6.10 and 5.80 respectively). The lowest doses of CT were detected for patients who underwent neck CT (3.30) (Table 3).

Table (3): X-ray and CT doses of different sites among the studied cases

\begin{tabular}{|l|c|c|cc|}
\hline Type of study & $\begin{array}{c}\text { No Of studies } \\
\text { Total: }\end{array}$ & $\begin{array}{l}\text { \% } 610) \\
\text { X ray }\end{array}$ & & :dian (Range) dose (mSv) \% \\
CT & 29 & 95.2 & & \\
\hline X ray Type: & $(\mathrm{n}=581)$ & 4.8 & & \\
CXR & 562 & 96.7 & 0.21 & $(0.09-0.35)$ \\
Upper \& lower extremities & 4 & 0.7 & 0.26 & $(0.22-1.08)$ \\
Wrist \& ankle & 2 & 0.3 & 0.23 & $(0.19-0.27)$ \\
Skull & 1 & 0.2 & 0.17 & \\
Spinal cord & 4 & 0.7 & 0.40 & \\
Abdomen & 4 & 0.7 & 0.63 & $(0.21-1)$ \\
Body bone & 1 & 0.2 & 0.16 & \\
Chest \& abdomen & 1 & 0.2 & 0.26 & \\
Chest \& Neck & 1 & 0.2 & 0.30 & \\
Pelvic \& lower extremities & 1 & 0.2 & 0.26 & \\
\hline CT type: & $(\mathrm{n}=29)$ & & & \\
Chest & 21 & 72.4 & 6.10 & $(4.5-6.2)$ \\
Cerebral angiography & 1 & 3.4 & 7.50 & \\
Neck & 2 & 6.9 & 3.30 & $(3.2-3.4)$ \\
Brain & 5 & 17.2 & 5.80 & $(3.1-6.2)$ \\
\hline
\end{tabular}

Table (4) showed that the dose among the studied cases ranged from 0.197 to $15.37 \mathrm{mSv}$ with mean 4.73 $\mathrm{mSv}$. Regarding risk, $18.1 \%$ were very low, $55.6 \%$ were low, $23.6 \%$ were moderate and only $2.8 \%$ were high. Cumulative exposure dose that exceeded $15 \mathrm{mSv}$ (the cut off number decided from previous studies to reflect high dose exposure) was noticed in $2.8 \%(\mathrm{n}=2 \mathrm{pts}$ ) (Table 4 and Figure 1).

Table (4): Total dose among the studied cases

\begin{tabular}{|l|c|c|}
\hline Variable & $(\mathbf{n}=\mathbf{7 2})$ \\
\hline Dose: $(\mathbf{m S v})$ & \multicolumn{2}{|c|}{$4.73 \pm 3.97$} \\
\hline Mean \pm SD & \multicolumn{2}{|c|}{$0.197-15.37$} \\
\hline Median & \multicolumn{2}{|c|}{0} \\
\hline Range & $\mathbf{N}$ & \% \\
\hline Variable & & 18.1 \\
\hline Risk: & 13 & 55.6 \\
\hline V low & 40 & 23.6 \\
\hline Low & 17 & 2.8 \\
\hline Moderate & 2 & \\
\hline High & \multicolumn{2}{|c|}{} \\
\hline
\end{tabular}

Regarding risk, $18.1 \%$ were very low, $55.6 \%$ were low, $23.6 \%$ were moderate and only $2.8 \%$ were high (Figure 1 ). 


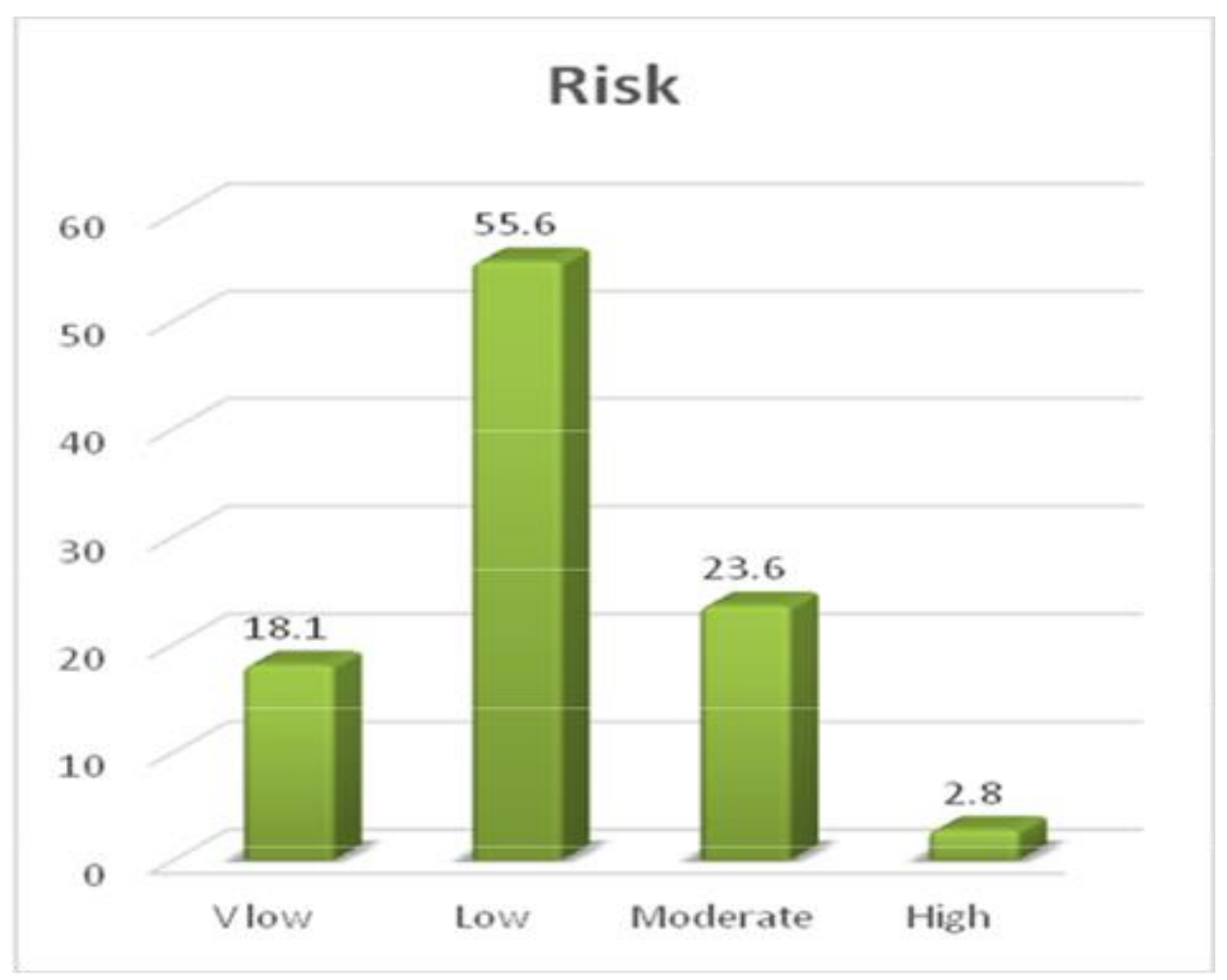

Figure (1): Risk among the studied cases

\section{DISCUSSION}

The median of x-ray + ct group was $3.7 \mathrm{msv}$ in contrast to $7.9 \mathrm{msv}$ in our study. Our median was higher in the 2 groups. Another pediatric subgroup study by Moloney et al. ${ }^{(5)}$, done on 23 patients with total exposure dose of $74.6 \mathrm{msv}$ and a median of .07 (total median of us 3.9). But the median of the whole group of this study (age from 1 to 93 ) is $1.5 \mathrm{msv}$. In this study of adults and pediatrics, $12 \%$ had exceeded 15 msv. However, in our pediatric study, $2.8 \%$ had exceeded $15 \mathrm{msv}$. This high percentage of CED in their study may be attributed to the difference in inclusion criteria as they included a trauma center, where radiologic requests are more frequent also, patients with trauma sometimes need CT for the whole body. Our higher median may be due to deficient training of our technicians and using adult parameters with children.

In addition, in our study, there was dose variation among units. The median of exposure of patients of chest unit was 6.51 . While the median of patients of ICU was 1.9. This may be attributed to different technicians and machines (personal and machine factors).

The total images done were 610 study, $95.2 \%$ were $\mathrm{x}$-ray and $4.8 \%$ were CT. The most frequent study in both types was chest image and this agrees with a study of Moloney et al. ${ }^{(5)}$, where chest radiography was the most commonly performed examination of about $83 \%$ of all studies and CT accounted for $16 \%$.

Dose of CT in our study formed $53.8 \%$ of the total CED in spite of representing only about $4.5 \%$ of all studies while dose of $\mathrm{x}$-ray films formed $46.2 \%$ of the total CED although representing about $95.2 \%$ of the total studies. This big CED due to CT scans in relation to their low percentage of the whole studies also agrees with the study of Moloney et al. ${ }^{(5)}$, where the $21 \mathrm{CT}$ scans formed $98 \%$ of their total CED.

In our study, there was no significant relation between CED and length of stay in contrast to the study of Moloney $\boldsymbol{e t}$ al. ${ }^{(5)}$, in which high CED was associated with extended ICU admission. This is because our patients stayed for a short period and in the same time performed many images and vice versa, may stay for a long period with few image performances. It is known that chest CT may give radiation dose equaling up to 150 -chest x-ray ${ }^{(7)}$.

Our study revealed that CT chest equaled about 30 -chest x-ray in our hospital. This variation might be due to the higher chest $\mathrm{x}$-ray doses given to children by technicians while the CT doses are approximately similar.

This result of higher chest $\mathrm{x}$-ray doses coincides with a study done in Egypt by Ahmed ${ }^{(8)}$, which revealed that the average entrance skin dose values of Egyptian pediatric chest radiographs (ranged from .04 - 0.4) are higher than that of international reference values of National Radiological Protection Board (.05 - 0.12). (The range in our study is from .09 to 0.35). Patients included in the study were exposed to doses ranged from .19 to $15.37 \mathrm{msv}$.

Although approximately $74 \%$ of patients had very low and low risks. The results should be put in mind as epidemiological studies had presented evidence of increased mortality related to cancer after 
exposure to low doses of diagnostic imaging ionizing radiation ${ }^{(9)}$.

Moreover, the biological effects from Ionizing Radiation report showed that risk of cancer follows a linear model with low exposure doses and that even the smallest dose can cause a small increase in humans' risk. In addition, about one person in one hundred is expected to have cancer from $100 \mathrm{msv}$ dose ${ }^{(6)}$. Another study also estimated that about $.9 \%$ of malignant tumours in the United States caused by diagnostic imaging per year ${ }^{(\mathbf{1})}$.

\section{CONCLUSION}

Cumulative exposure dose (CED) of ionizing radiation due to frequent x-ray films and CT scans in our study are not likely to cause acute toxicity as they were relatively low but they may cause chronic toxicity and increases the long-term risk for developing malignancy. From our study, 2.8\% had exceeded CED of $15 \mathrm{msv}$ and included in high-risk exposure. Most studies were x-ray, most of them were in the Chest Unit and most of CED resulted from CT studies.

\section{REFERENCES}

1. Barrington de Gonzalez A, Darby S (2004): Risk of cancer from diagnostic X-rays: Estimates for the UK and 14 other countries. Lancet, 363: 345-351.

2. Weiner D, Maity A, Carlson C et al. (2006): Pulmonary function abnormalities in children treated with whole lung irradiation. Pediatric Blood Cancer, 46: $222-227$.
3. Fazel R, Krumholz H, Wang Y et al. (2009): Exposure to low-dose ionizing radiation from medical imaging procedures. N Engl J Med., 361: 849-857.

4. United Nations Scientific Committee on the Effect of Atomic Radiation (UNSCEAR) (2006): Sources, effects and risks of ionizing radiation. United Nations Scientific Committee on the Effects of Atomic Radiation, United Nations, New York, NY. Available at: www.unscear.org/unscear/en/publications/2006_1.ht $\mathrm{ml}$ - accessed December 2009.

5. Moloney F, Fama D, Twomey M et al. (2016): Cumulative radiation exposure from diagnostic imaging in intensive care unit patients. World $\mathbf{J}$ Radiol., 8 (4): 419-27.

6. National Research Council (2006): Health risks from exposure to low levels of ionizing radiation: BEIR Vll phase 2. Washington DC: National Academy of Sciences. https://www.nap.edu/catalog/11340/health-risksfrom-exposure-to-low-levels-of-ionizing-radiation

7. Mettler F, Huda W, Mahesh M (2008): Effective doses in radiology and diagnostic nuclear medicine: a catalog. Radiology, 248 (1): 254-63.

8. Ahmed T (2019): Measurements of Entrance Skin Dose in Egyptian Pediatric during Diagnostic X-Rays using Thermo Luminescence Dosimeter (TLD -100). Arab Journal of Nuclear Sciences and Applications, 52: $1-5$.

9. Ronckers C, Erdmann C, Land C (2005): Radiation and breast cancer: a review of current evidence. Breast Cancer Res., 7: 21-32. 